\title{
Influência da produtividade da cana-de-açúcar no custo do corte mecanizado
}

Influence of sugarcane productivity in mechanized cutting cost

\author{
Kamyro Jorge José Zaccaria Bastos ${ }^{1}$; Marcos Guimarães de Andrade Landell² \\ Elisângela de Souza Miranda*3
}

\section{Resumo}

A cultura da cana-de-açúcar possui grande relevância dentro do agronegócio nacional. Na safra 2014/2015, o Brasil produziu 634,8 milhões de toneladas em um pouco mais de nove milhões de hectares cultivados principalmente nos Estados de São Paulo, Goiás, Minas Gerais, Paraná e Mato Grosso do Sul, gerando grande quantidade de empregos diretos e indiretos. No processo de produção da cana a colheita destaca-se pelos altos custos, representando aproximadamente $35 \%$ do custo total de produção, sendo que o corte mecanizado é responável por $53 \%$ desta parcela. A definição deste custo é consequência de algumas variáveis, mas principalmente influenciado pela produtividade agrícola, já que o rendimento de colheita do equipamento depende basicamente da relação entre velocidade de colheita e produtividade do canavial. Neste contexto, objetivou-se avaliar a influência da produtividade agrícola no custo do corte mecanizado da cultura em uma unidade agroindustrial localizada no estado de Goiás. Constatou-se que o aumento de produtividade foi fundamental para 0 aumento no rendimento de colheita, reduzindo os custos deste processo. Conclui-se que quanto maior a produtividade agrícola, menor o custo do corte mecanizado, em função da necessidade de menor utilização da quantidade de horas de colhedoras para realizar o corte mecanizado da área estudada, que foi de 21.496 ha. O custo do corte mecanizado foi reduzido em $27,9 \%$ devido ao aumento de $31,09 \%$ da produtividade agrícola. A redução do custo foi de 2,88 milhões de reais no período estudado.

Palavras-chave: colheita mecanizada, rendimento, Saccharum spp

\begin{abstract}
The culture of sugarcane has great relevance in the national agribusiness. Sugarcane has great relevance within the national agribusiness. In the 2014/2015 harvest, Brazil produced 634.8 million tons over nine million $(9,000,000)$ hectares cultivated mainly in the states of São Paulo, Goiás, Minas Gerais, Paraná and Mato Grosso do Sul, emerging large amount of direct and indirect jobs. In the sugarcane production process, the harvesting stands out because of its high costs, representing approximately $35 \%$ of the total cost of production. Mechanized cutting represents $53 \%$ of the harvesting cost. Several variables influence this cost, the main one is yield, since the productivity of the harvesting equipment depends on the relationship between the harvester speed and the cane yield. In this context, the purpose of this study was to evaluate the influence of sugarcane yield in the cost of mechanical harvesting at agroindustrial unit in the state of Goiás. It was found that the sugarcane yield increase was the key to increase the harvesters' productivity, reducing the cost of this process. Concludes that the higher the crop yield, the lower the cost of mechanical cutting depending on the need to use the lowest amount of harvesters hours to perform mechanical cutting of the studied area, which was 21 $496 \mathrm{~h}$. The cost of mechanical cutting was reduced by $27.9 \%$ due to the increase of $31.09 \%$ agricultural productivity. Reducing the cost was 2.88 million reais in the period studied.
\end{abstract}

Keywords: mechanized harvest, yield, Saccharum spp

\footnotetext{
"Autor correspondente <elisangela.miranda@usp.br> Enviado: 05 ago. 2016 Aprovado: 19 set. 2016
} 


\section{Introdução}

Atualmente a cultura da cana-de-açúcar ocupa no Brasil uma área de aproximadamente $9.098,03$ mil hectares, correspondendo a uma produção total na safra 2014/2015 de 659,10 milhões de toneladas (CONAB, 2014).

O maior produtor é o estado de São Paulo com 51,43\% da área plantada. O estado de Goiás possui 9,85\%, Minas Gerais tem participação em 8,8\%, seguido por Mato Grosso com 7,63\% e Paraná com 7,07\%. Os estados do Nordeste, como Alagoas e Pernambuco possuem 4,41\% e 2,89\%, respectivamente. A soma dos sete estados mencionados representa $92,07 \%$ do total da área plantada com a cultura no Brasil (CONAB, 2014).

A produção dos derivados da cana-de-açúcar na região Centro-Sul do Brasil se desenvolve entre abril e novembro, quando há maior concentração de açúcar total recuperável $[\mathrm{ATR}]$ na planta e menor incidência de chuvas, o que viabiliza a colheita. Nesse período, o maior compromisso da área agrícola das unidades agroindustriais é garantir o abastecimento contínuo de matéria prima. Para que isso aconteça, é necessário gerenciar os fatores que interferem no corte, carregamento e transporte da lavoura até a indústria.

A colheita da cana-de-açúcar possui grande importancia no processo produtivo, pois seu custo representa aproximadamente $35 \%$ do custo total de produção da cultura. O corte mecanizado é reponsável por $53 \%$ desta parcela, o carregamento por $15 \%$ e o transporte por $32 \%$ (IDEA, 2008). O aumento da mecanização é fundamental para a agricultura que busca elevada produtividade com custo reduzido. O aumento da inovação neste processo evidencia o desenvolvimento desta atividade, que teve sua origem com o corte manual (Veiga Filho,1999).

Para Silva (2002), a produção canavieira, especialmente no que se refere à mecanização, tem três dimensões: uma tecnológica, uma organizacional e uma que trata da relação com as unidades para dentro e para fora do complexo sucroalcooleiro. É necessário que ocorram alterações na área agrícola e industrial, inclusive na articulação de ambas. $O$ corte mecânico de cana representa a mecanização do último elo de fornecimento de cana à unidade agroindustrial que ainda restava.

A princípio, o corte mecanizado era realizado em cana queimada, prática realizada com intuito de eliminar a palha e facilitar a colheita. Contudo, a partir de pressões constantes de entidades ambientais, a forma de colheita da cana-de-açúcar vem sofrendo alterações, prevalecendo, atualmente, a colheita da cana crua, ou seja, sem o uso do fogo para eliminação da palha. 
Após a década de 1970 as primeiras colhedoras de cana foram concebidas, com objetivo de cortar, picar, limpar e carregar a cana em um unico equipamento, porém a mecanização do corte ganhou expressão após a década de 1990. Esse movimento da mecanização do corte desta cultura teve sua origem devido as demandas geradas pelo programa gorvernamental denominado de proálcool, pois com a elevada expansão houve necessidade de grande incremento de mão de obra braçal, que tinha limitações em algumas regiões (Vieira e Simon, 2005).

Os principais ganhos derivados da colheita mecanizada e que proporcionaram grandes avanços a cultura canavieira no país foram a redução de custo dessa atividade e o aumento da produtividade do trabalho, reduzindo a mão de obra no processo (Vieira e Simon, 2005). Porém, nas diferentes regiões produtoras a mecanização do corte ocorreu em intensidades diferentes. Um dos principais fatores é a restrição dos equipamentos em áreas com maior declividade, como o caso da região nordeste. Outro fator relevante é o custo inicial dos equipamentos, portanto em regiões que a mão de obra era mais abundante o processo de mecanização foi retardado (Vieira e Simon, 2005).

Segundo Scopinho et al. (1999), para a utilização do corte mecanizado torna-se necessário que algumas condições físicas, técnicas e de produtividade agrícola sejam atendidas, caso contrário o custo do processo mecanizado ultrapassaria o custo do corte manual, injustificando a adoção da tecnologia. Com o aumento do rendimento do corte da cultura, através da mecanização, os custos são reduzidos entre $50 \%$ e $60 \%$ em relação ao custo total da produção agrícola, além da melhoria da qualidade da matéria prima.

Silva et al. (2002) relatam que para o sucesso da mecanização do corte é necessário propriedades de grande porte, acima de 500 ha, ou um conjunto de propriedades menores interligadas. Além da necessidade de escala operacional, o fator produtividade do canavial também possui importante relevancia no rendimento dos equipamentos.

Diante do exposto, objetivou-se avaliar a influência da produtividade agrícola no custo do corte mecanizado da cultura em uma unidade agroindustrial localizada no estado de Goiás.

\section{Materiais e Métodos}

O estudo foi realizado em uma unidade agroindustrial de cana-de-açúcar localizada no norte do estado de Goiás. Atualmente esta empresa processa 1,5 
milhões de toneladas por ano e possui área produtiva de 19 mil ha. Toda colheita ocorre pelo sistema mecanizado com período de safra definido entre abril e dezembro.

Para as informações de disponibilidade climática, foram utilizadas as informações da estação climática da empresa. Considerou indisponibilidade climática os dias com apontamento de chuvas superiores a $5 \mathrm{~mm}$ durante as 24 horas. Para encontrar a disponibilidade climática mensal média, utilizou-se a quantidade de dias indisponíveis em relação aos dias totais disponíveis no mês.

Os dias efetivos foram considerados o total dos dias disponíveis, que por consequência não tiveram incidência de chuvas, através da multiplicação dos dias disponíveis no mês pela porcentagem de disponibilidade climática.

Em relação à disponibilidade industrial, foi considerado o realizado do período analisado. Utilizou para o cálculo a quantidade de paradas indústrias em relação às horas totais possíveis de moagem. Observa-se um elevado aproveitamento de tempo, devido à unidade industrial ter iniciado suas atividades em 2011.

O volume de moagem foi considerado o da última safra, aproximando-o para 1,5 milhões de toneladas. Para elaboração do modelo, foi utilizada a distribuição da moagem em função dos dias disponíveis por mês, mantendo a moagem diária equivalente para todos os dias.

A produtividade da cana-de-açúcar da região está relacionada a diversos fatores de ordem edafoclimáticas e de manejo, contemplando os sistemas de irrigação instalados em $35 \%$ das áreas agricultáveis.

Nesta pesquisa a variável produtividade é importante, pois está relacionada diretamente ao rendimento das colhedoras. A capacidade de corte mecanizado de uma colhedora é expressa pela eq.(1), a qual evidencia a importante participação da produtividade da cana-de-açúcar na capacidade potencial da colhedora:

$$
\text { Cpot }=\frac{\text { Velocidade } * \mathrm{TCH} * \mathrm{n} \text {-linhas } * \text { espaçamento }}{10}
$$

onde, Cpot: Capacidade potencial da colhedora $\left(\mathrm{t} \mathrm{h}^{-1}\right)$; Velocidade: Velocidade da colhedora $\left(\mathrm{km} \mathrm{h}^{-1}\right)$; $\mathrm{TCH}$ : toneladas de cana por hectare ( $\left.\mathrm{t} \mathrm{ha}^{-1}\right)$; № Linhas: Número de linhas que a colhedor colhe simultaneamente (unidade); Espaçamento: Espaçamento entre as linhas de plantio de cana $(\mathrm{m})$.

Os dados de produtividade foram retirados do sistema de gerenciamento agrícola da empresa, através do uso de computadores de bordo dos equipamentos. 
Foram consideradas as produtividades realizadas mensalmente nos anos de 2011, $2012,2013,2014$. A produtividade mensal foi determinada pelo volume de cana processado, mensurado pela pesagem na balança da indústria, dividido pela quantidade de talhões colhidos, identificado através das ordens de serviços de cada talhão.

Este estudo considerou apenas a produtividade como variável, mantendo todos os demais indicadores constantes. Neste contexto, foi possível mensurar o efeito de sua variação no custo do corte mecanizado.

Para identificar os tempos operacionais das colhedoras, foi utilizada a base de dados dos computadores de bordos no período estudado (2011 a 2014) e utilizado para efeito de análise neste estudo a média do período. Os dados referentes às velocidades das colhedoras foram utilizados as informações dos computadores de bordo do mesmo período. Foi selecionando, no entanto, as colhedoras que tiveram os dados mais consistentes, já que ao longo das quatro safras estudadas alguns equipamentos possuíam grandes desvios

A utilização do equipamento foi encontrada através da relação entre horas utilizadas (horas trabalhadas + horas auxiliares) e horas disponíveis (horas trabalhadas + horas auxiliares + horas Perdidas). Essa análise permitiu avaliar 0 efeito das horas perdidas sobre o desempenho do equipamento. Valores baixos indicam grande quantidade de horas perdidas por dia de operação executada pelo equipamento.

As informações de disponibilidade mecânica foram mensuradas através de todos os motivos de paradas relacionado a manutenção do equipamento, incluindo a manutenção primária, como lavagem, lubrificação e abastecimento. Essa variável identifica a disponibilidade do equipamento para o trabalho, considerando-se como indisponibilidade o tempo de manutenção mecânica. O rendimento nominal das colhedoras foi definido pela eq. (2):

$$
\text { Rendimento nominal da colhedora }=\left(\text { velocidade }\left(\frac{K m}{h}\right) *\left(\text { produtividade }\left(\frac{t}{h a}\right) \mid \text { metros lineares }(m)\right) * 100\right.
$$

Tanto as variáveis velocidade e produtividade possuem influência direta no rendimento do equipamento. A quantidade de metros lineares foi constante neste estudo, pois o espaçamento de plantio da cultura na empresa analisada sempre foi de 1,5 metros. Portanto, o volume de metros lineares por hectare plantado é igual a 6.666 
metros lineares a cada 10.000 metros quadrados de terra. $O$ rendimento efetivo das colhedoras foi definido pela eq. (3):

$$
\text { Rendimento efeitvo }=R N *(\% \text { Disponibilidade Mecânica } * \text { \%tilização })
$$

onde, RN: é o rendimento nominal da colhedora.

O rendimento efetivo da colhedora desconsidera o tempo não produtivo, ou seja, o período utilizado para manutenções, abastecimento, deslocamento, lavagem, entre outros. Para estabelecer o rendimento diário da colhedora foi utilizado o rendimento efetivo multiplicado pelas 24 horas disponíveis em um dia de trabalho, resultando na eq.(4):

$$
\text { Redimento efetivo }\left(\frac{t}{\text { hora }}\right) * 24 \text { horas }
$$

O dimensionamento das colhedoras foi realizado considerando a moagem mensal necessária, o rendimento efetivo da colhedora em um dia de trabalho e a quantidade de dias úteis disponíveis no mês, conforme eq.(5):

$$
\text { Necessidade de colhedoras }=\frac{\text { Moagem mensal }}{\text { Rendimento diário da colhedora }\left(\frac{t}{\text { dia }}\right) * \text { dias úteis }}
$$

Para definição das horas necessárias para colheita do volume de cana planejado foi utilizando a moagem mensal e o rendimento nominal do equipamento. Portanto, quando o equipamento está efetivamente trabalhando, o mesmo opera em seu rendimento nominal dentro das horas efetivas de colheita. A eq.(6) representa a necessidade de horas de colhedoras.

$$
\text { Horas necessárias }=\left(\frac{\text { Moagem Mensal }}{\text { rendimento nominal }}\right)
$$

Os valores monetários foram expressos em dólar americano considerando o câmbio do dia 15 de abril de 2015, para que não ocorra a perda da referência dos dados em curto lapso de tempo.

É importante salientar que no presente estudo, a análise foi realizada durante quatro safras. Por esse motivo não foi considerado os casos de tombamento por ser 
exceção e ter pouca influência no rendimento médio da colheita. Em casos de tombamento, o maior impacto é em relação às perdas e impurezas e não, obrigatoriamente no rendimento dos equipamentos.

\section{Resultados e Discussão}

A produtividade agrícola da unidade agroindustrial analisada neste estudo apresentou aumento sucessivo ao longo das últimas quatro safras. Este incremento ocorreu devido a diversos manejos agronômicos e o intensivo cuidado para evitar a compactação do solo, em função do tráfego dos equipamentos.

Os principais manejos agronômicos observados como diferenciais para incrementar a produtividade, foram: a utilização de matriz ambiental para definir época de plantio, colheita e definição da variedade, irrigação complementar e de salvamento em 35\% da área cultivada, aumento da adubação no fundo do sulco na época do plantio, utilização de micros nutrientes (tanto na adubação de plantio como nos tratos culturais de soca) e aplicação de herbicidas em taxa variada, considerando as características do solo, argila, CTC e matéria orgânica.

A Tabela 1 evidencia a evolução da produtividade média do canavial da empresa analisada nas ultimas quatro safras. $O$ incremento de produtividade foi de $32 \%$ entre as safras de 2011 a 2014.

Tabela 1. Produtividade, em toneladas por hectare, mensal realizada entre as safras de 2011 a 2014

\begin{tabular}{ccccccccccc}
\hline Safra & Abr & Maio & Jun & Jul & Ago & Set & Out & Nov & Dez & Média \\
\hline 2011 & 72,77 & 73,02 & 81,86 & 80,36 & 82,77 & 72,44 & 70,85 & 68,54 & 63,36 & $\mathbf{7 5 , 3 6}$ \\
2012 & 79,68 & 91,91 & 89,51 & 95,92 & 90,14 & 74,03 & 64,55 & 63,74 & 61,28 & $\mathbf{8 1 , 7 9}$ \\
2013 & 82,97 & 95,41 & 96,95 & 111,20 & 106,58 & 93,96 & 81,08 & 88,42 & 111,19 & $\mathbf{9 6 , 2 4}$ \\
2014 & 99,63 & 107,95 & 117,34 & 110,85 & 99,60 & 92,73 & 83,55 & 78,08 & 86,97 & $\mathbf{9 9 , 5 4}$
\end{tabular}

Fonte: Dados obtidos da propriedade em estudo com base nas safras 2011 a 2014

Este aumento de produtividade foi fundamental para o aumento no rendimento de colheita, reduzindo os custos deste processo. Além da produtividade, a velocidade de colhedora influência de forma determinante no processo da colheita mecanizada.

Com objetivo de isolar a variável produtividade, como principal influenciadora para redução de custo da colheita, considerou-se a velocidade constante em todas as análises. 
A Tabela 2 resume todas as amostras, de cada equipamento, coletado via computador de bordo nos últimos quatro anos. Foram 26.228 amostras com velocidade média de $3,72 \mathrm{~km} \mathrm{~h}^{-1}$.

Para as simulações, considerou ao longo das quatro safras a velocidade média citada, variando apenas a produtividade.

Tabela 2. Velocidade média das colhedoras analisadas

\begin{tabular}{ccc}
\hline Colhedora & Amostras & Média $\left(\mathrm{km} \mathrm{h}^{-1}\right)$ \\
\hline 1 & & 3,22 \\
2 & 2.052 & 3,45 \\
3 & 1.652 & 3,55 \\
4 & 1.748 & 3,89 \\
5 & 1.780 & 3,54 \\
6 & 2.392 & 3,10 \\
7 & 1.860 & 3,47 \\
8 & 1.700 & 3,90 \\
9 & 1.784 & 4,40 \\
10 & 2.296 & 4,27 \\
11 & 2.320 & 3,27 \\
12 & 1.924 & 3,98 \\
13 & 2.296 & 4,37 \\
\hline Total/média & 2.424 & 3,724 \\
\hline
\end{tabular}

Fonte: Dados obtidos da propriedade em estudo com base nas safras 2011 a 2014

Abaixo foram realizadas quatro simulações de colheita, utilizando modelo matemático realizado em Excel (Tabelas 3 a 6 e Figuras 1 a 4).

O modelo considerou todas as variáveis envolvidas no processo de colheita mecanizada. Como o objetivo deste estudo foi analisar a influência da produtividade agrícola no custo de colheita, as demais variáveis foram consideradas constantes ao longo das safras e dos meses de colheita. Todos os valores para demais variáveis foram considerados os realizados pela unidade agroindustrial, considerando a média das quatro safras analisadas.

O volume de cana colhida ao longo da safra foi de 1,5 milhões de toneladas. A utilização dos equipamentos foi de $62 \%$ e a disponibilidade mecânica de $85 \%$.

Para as variáveis disponibilidade climática, dias efetivos e disponibilidade industrial a variação ocorre mês a mês, porém em todas as quatro simulações os valores são iguais. 
Conforme modelagens abaixo se observam a influência direta da produtividade da cana-de-açúcar no rendimento de colheita. Quanto maior a produtividade, maior o rendimento de colheita dos equipamentos e menor a quantidade de horas máquinas necessárias para realizar o processo de corte mecânico. Por consequência da variação da produtividade agrícola, em relação ao rendimento dos equipamentos, observa-se também a alteração na demanda por colhedoras nas quatro safras analisadas.

Tabela 3: Modelagem para dimensionar o volume de horas necessárias para colheita de 1,5 milhões de toneladas na safra 2011 , em função das produtividades mensais da cana-de-açúcar

\begin{tabular}{|c|c|c|c|c|c|c|c|c|c|c|}
\hline \multicolumn{11}{|c|}{ Safra 2011} \\
\hline Indicadores & Unid. & Abr & Maio & Jun & Jul & Ago & Set & Out & Nov & Dez \\
\hline $\begin{array}{l}\text { Dias do Mês } \\
\text { (dias de safra) }\end{array}$ & $d$ & 30 & 31 & 30 & 31 & 31 & 30 & 31 & 30 & 15 \\
\hline $\begin{array}{l}\text { Disponibilidade } \\
\text { Climática }\end{array}$ & $\%$ & 83 & 99 & 93 & 100 & 99 & 92 & 80 & 66 & 62 \\
\hline Dias Efetivos & $d$ & 23 & 30 & 27 & 30 & 30 & 27 & 24 & 19 & 9 \\
\hline $\begin{array}{l}\text { Disponibilidade } \\
\text { Industrial }\end{array}$ & $\%$ & 94 & 97 & 97 & 97 & 97 & 97 & 96 & 95 & 94 \\
\hline $\begin{array}{l}\text { Moagem Mensal } \\
\text { Planejada }\end{array}$ & mil t ha' & 161,8 & 204,1 & 186,1 & 207,9 & 204,1 & 183,5 & 163,5 & 130,2 & 58,8 \\
\hline $\begin{array}{l}\text { Produtividade } \\
\text { Média Mensal }\end{array}$ & $t_{\text {ha }}^{-1}$ & 72,77 & 73,02 & 81,86 & 80,36 & 82,77 & 72,44 & 70,85 & 68,54 & 63,36 \\
\hline $\begin{array}{l}\text { Características } \\
\text { da Colhedora }\end{array}$ & Unid. & Abr & Mai & Jun & Jul & Ago & Set & Out & Nov & Dez \\
\hline $\begin{array}{l}\text { Velocidade } \\
\text { Média de } \\
\text { Colheita }\end{array}$ & $\mathrm{km} \mathrm{h}^{-1}$ & 3,7 & 3,7 & 3,7 & 3,7 & 3,7 & 3,7 & 3,7 & 3,7 & 3,7 \\
\hline Utilização & $\%$ & 0,62 & 0,62 & 0,62 & 0,62 & 0,62 & 0,62 & 0,62 & 0,62 & 0,62 \\
\hline $\begin{array}{l}\text { Disponibilidade } \\
\text { Mecânica }\end{array}$ & $\%$ & 0,85 & 0,85 & 0,85 & 0,85 & 0,85 & 0,85 & 0,85 & 0,85 & 0,85 \\
\hline $\begin{array}{l}\text { Rendimento } \\
\text { Nominal }\end{array}$ & $\mathrm{th}^{-1}$ & 40 & 41 & 45 & 45 & 46 & 40 & 39 & 38 & 35 \\
\hline $\begin{array}{l}\text { Rendimento } \\
\text { Efetivo }\end{array}$ & $t h^{-1}$ & 21,3 & 21,4 & 23,9 & 23,5 & 24,2 & 21,2 & 20,7 & 20,0 & 18,5 \\
\hline $\begin{array}{l}\text { Rendimento Por } \\
\text { dia estimado }\end{array}$ & $\mathrm{th}^{-1}$ & 511 & 513 & 575 & 564 & 581 & 509 & 497 & 481 & 445 \\
\hline Colhedoras & № & 14 & 14 & 13 & 13 & 12 & 14 & 14 & 15 & 16 \\
\hline $\begin{array}{l}\text { Horas } \\
\text { Necessárias }\end{array}$ & $\mathrm{h}$ & 4.016 & 5.036 & 4.096 & 4.660 & 4.442 & 4.564 & 4.158 & 3.423 & 1.671 \\
\hline
\end{tabular}

Fonte: Dados obtidos da propriedade em estudo com base na safra 2011 


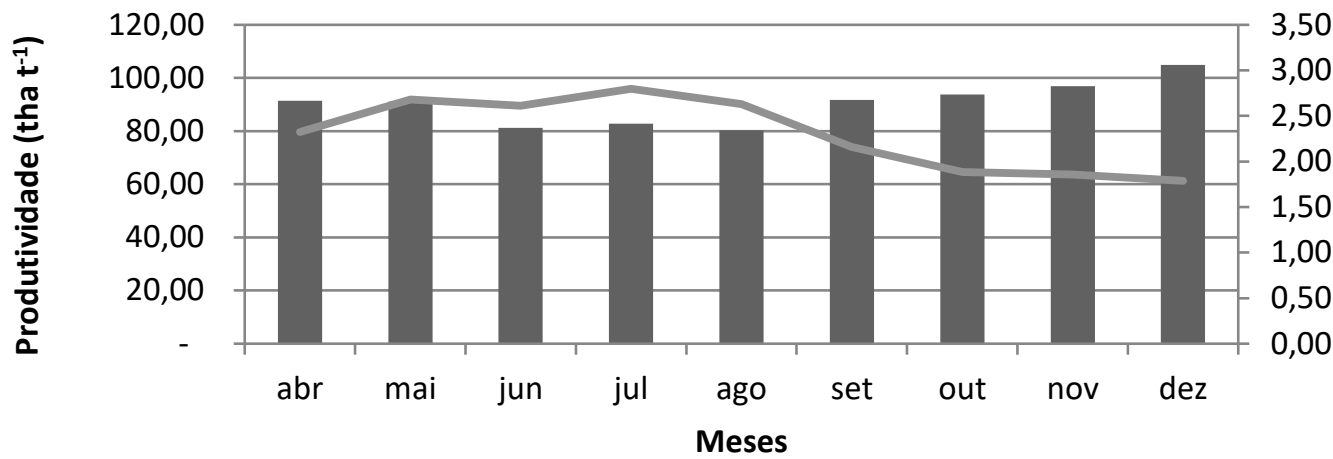

ț

USD por t-1 — Produtividade

Figura 1. Relação entre o custo do corte mecanizado de uma tonelada e a produtividade da cana-de-açúcar durante os meses da safra 2011

Fonte: Dados obtidos da propriedade em estudo com base na safra 2012

Tabela 4. Modelagem para dimensionar o volume de horas necessárias para colheita de 1,5 milhões de toneladas na safra 2012 , em função das produtividades mensais da cana-de-açúcar

\begin{tabular}{|c|c|c|c|c|c|c|c|c|c|c|}
\hline \multicolumn{11}{|c|}{ Safra 2012} \\
\hline Indicadores & Unid. & Abr & Maio & Jun & Jul & Ago & Set & Out & Nov & Dez \\
\hline $\begin{array}{l}\text { Dias do Mês (dias } \\
\text { de safra) }\end{array}$ & Dias & 30 & 31 & 30 & 31 & 31 & 30 & 31 & 30 & 15 \\
\hline $\begin{array}{l}\text { Disponibilidade } \\
\text { Climática }\end{array}$ & $\%$ & 83 & 99 & 93 & 100 & 99 & 92 & 80 & 66 & 62 \\
\hline Dias Efetivos & Dias & 23 & 30 & 27 & 30 & 30 & 27 & 24 & 19 & 9 \\
\hline $\begin{array}{l}\text { Disponibilidade } \\
\text { Industrial }\end{array}$ & $\%$ & 94 & 97 & 97 & 97 & 97 & 97 & 96 & 95 & 94 \\
\hline $\begin{array}{l}\text { Moagem Mensal } \\
\text { Planejada }\end{array}$ & mil t ha ${ }^{-1}$ & 161,8 & 204,1 & 186,1 & 207,9 & 204,1 & 183,5 & 163,5 & 130,2 & 58,8 \\
\hline $\begin{array}{l}\text { Produtividade Média } \\
\text { Mensal }\end{array}$ & $\mathrm{t} \mathrm{ha}^{-1}$ & 79,68 & 91,91 & 89,51 & 95,92 & 90,14 & 74,03 & 64,55 & 63,74 & 61,28 \\
\hline $\begin{array}{l}\text { Características da } \\
\text { Colhedora }\end{array}$ & Unid. & Abr & Mai & Jun & Jul & Ago & Set & Out & Nov & Dez \\
\hline $\begin{array}{l}\text { Velocidade Média } \\
\text { de Colheita }\end{array}$ & $\mathrm{Km} \mathrm{h}^{-1}$ & 3,7 & 3,7 & 3,7 & 3,7 & 3,7 & 3,7 & 3,7 & 3,7 & 3,7 \\
\hline Utilização & $\%$ & 0,62 & 0,62 & 0,62 & 0,62 & 0,62 & 0,62 & 0,62 & 0,62 & 0,62 \\
\hline $\begin{array}{l}\text { Disponibilidade } \\
\text { Mecânica }\end{array}$ & $\%$ & 0,85 & 0,85 & 0,85 & 0,85 & 0,85 & 0,85 & 0,85 & 0,85 & 0,85 \\
\hline $\begin{array}{l}\text { Rendimento } \\
\text { Nominal }\end{array}$ & $\mathrm{th}^{-1}$ & 44 & 51 & 50 & 53 & 50 & 41 & 36 & 35 & 34 \\
\hline Rendimento Efetivo & $\mathrm{th}^{-1}$ & 23,3 & 26,9 & 26,2 & 28,1 & 26,4 & 21,7 & 18,9 & 18,6 & 17,9 \\
\hline $\begin{array}{l}\text { Rendimento Por dia } \\
\text { estimado }\end{array}$ & $\mathrm{th}^{-1}$ & 559 & 645 & 628 & 673 & 633 & 520 & 453 & 447 & 430 \\
\hline Colhedoras & № & 13 & 11 & 12 & 11 & 11 & 14 & 16 & 16 & 16 \\
\hline Horas Necessárias & Horas & 3.658 & 4.001 & 3.746 & 3.904 & 4.079 & 4.466 & 4.565 & 3.681 & 1.728 \\
\hline
\end{tabular}

Fonte: Dados obtidos da propriedade em estudo com base na safra 2012 


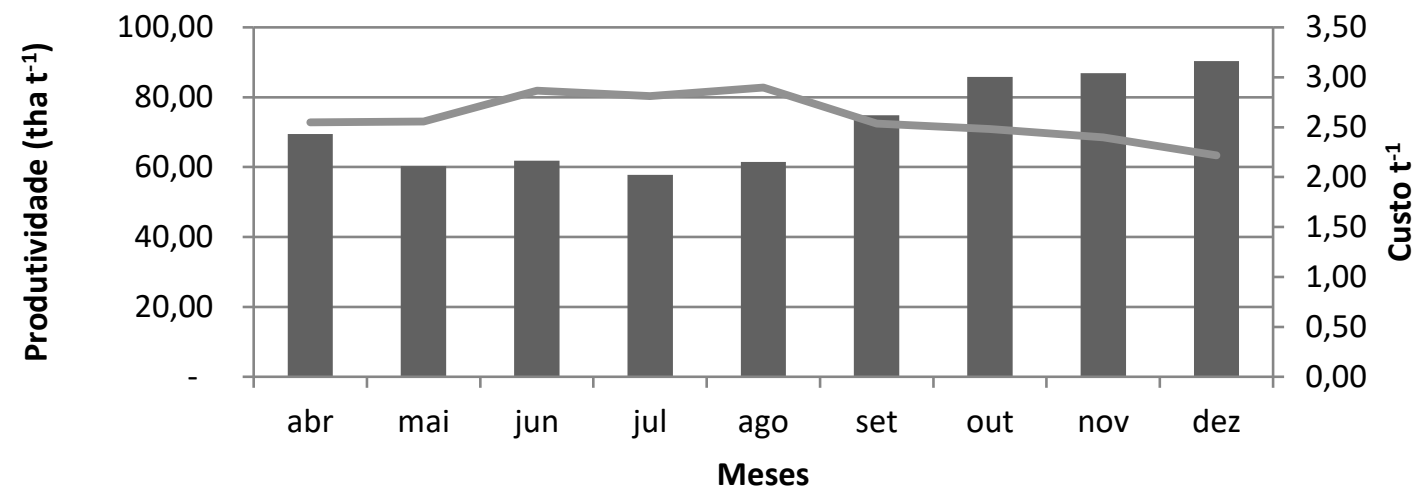

USD por t-1 Produtividade

Figura 2. Relação entre o custo do corte mecanizado de uma tonelada e a produtividade da cana-de-açúcar durante os meses da safra 2012 Fonte: Dados obtidos da propriedade em estudo com base na safra 2012

Tabela 5. Modelagem para dimensionar o volume de horas necessárias para colheita de 1,5 milhões de toneladas na safra 2013 , em função das produtividades mensais da cana-de-açúcar

\begin{tabular}{|c|c|c|c|c|c|c|c|c|c|c|}
\hline \multicolumn{11}{|c|}{ Safra 2013} \\
\hline Indicadores & Unid. & Abr & Maio & Jun & Jul & Ago & Set & Out & Nov & Dez \\
\hline $\begin{array}{l}\text { Dias do Mês (dias } \\
\text { de safra) }\end{array}$ & Dias & 30 & 31 & 30 & 31 & 31 & 30 & 31 & 30 & 15 \\
\hline $\begin{array}{l}\text { Disponibilidade } \\
\text { Climática }\end{array}$ & $\%$ & 83 & 99 & 93 & 100 & 99 & 92 & 80 & 66 & 62 \\
\hline Dias Efetivos & Dias & 23 & 30 & 27 & 30 & 30 & 27 & 24 & 19 & 9 \\
\hline $\begin{array}{l}\text { Disponibilidade } \\
\text { Industrial }\end{array}$ & $\%$ & 94 & 97 & 97 & 97 & 97 & 97 & 96 & 95 & 94 \\
\hline $\begin{array}{l}\text { Moagem Mensal } \\
\text { Planejada }\end{array}$ & mil t ha-1 & 161,8 & 204,1 & 186,1 & 207,9 & 204,1 & 183,5 & 163,5 & 130,2 & 58,78 \\
\hline $\begin{array}{l}\text { Produtividade } \\
\text { Média Mensal }\end{array}$ & $\mathrm{t} \mathrm{ha}^{-1}$ & 82,97 & 95,41 & 96,95 & 111,20 & 106,58 & 93,96 & 81,08 & 88,42 & $\begin{array}{c}111,1 \\
9\end{array}$ \\
\hline $\begin{array}{l}\text { Características da } \\
\text { Colhedora }\end{array}$ & Unid. & Abr & Mai & Jun & Jul & Ago & Set & Out & Nov & Dez \\
\hline $\begin{array}{l}\text { Velocidade Média } \\
\text { de Colheita }\end{array}$ & $\mathrm{Km} \mathrm{h}^{-1}$ & 3,7 & 3,7 & 3,7 & 3,7 & 3,7 & 3,7 & 3,7 & 3,7 & 3,7 \\
\hline Utilização & $\%$ & 0,62 & 0,62 & 0,62 & 0,62 & 0,62 & 0,62 & 0,62 & 0,62 & 0,62 \\
\hline $\begin{array}{l}\text { Disponibilidade } \\
\text { Mecânica }\end{array}$ & $\%$ & 0,85 & 0,85 & 0,85 & 0,85 & 0,85 & 0,85 & 0,85 & 0,85 & 0,85 \\
\hline $\begin{array}{l}\text { Rendimento } \\
\text { Nominal }\end{array}$ & $\mathrm{th}^{-1}$ & 46 & 53 & 54 & 62 & 59 & 52 & 45 & 49 & 62 \\
\hline $\begin{array}{l}\text { Rendimento } \\
\text { Efetivo }\end{array}$ & $\mathrm{th}^{-1}$ & 24,3 & 27,9 & 28,4 & 32,5 & 31,2 & 27,5 & 23,7 & 25,9 & 32,5 \\
\hline $\begin{array}{l}\text { Rendimento Por } \\
\text { dia estimado }\end{array}$ & $\mathrm{th}^{-1}$ & 583 & 670 & 681 & 781 & 748 & 660 & 569 & 621 & 781 \\
\hline Colhedoras & № & 12 & 11 & 11 & 9 & 10 & 11 & 13 & 12 & 9 \\
\hline Horas Necessárias & Horas & 3.513 & 3.854 & 3.459 & 3.368 & 3.450 & 3.518 & 3.634 & 2.653 & 952 \\
\hline
\end{tabular}

Fonte: Dados obtidos da propriedade em estudo com base na safra 2013 


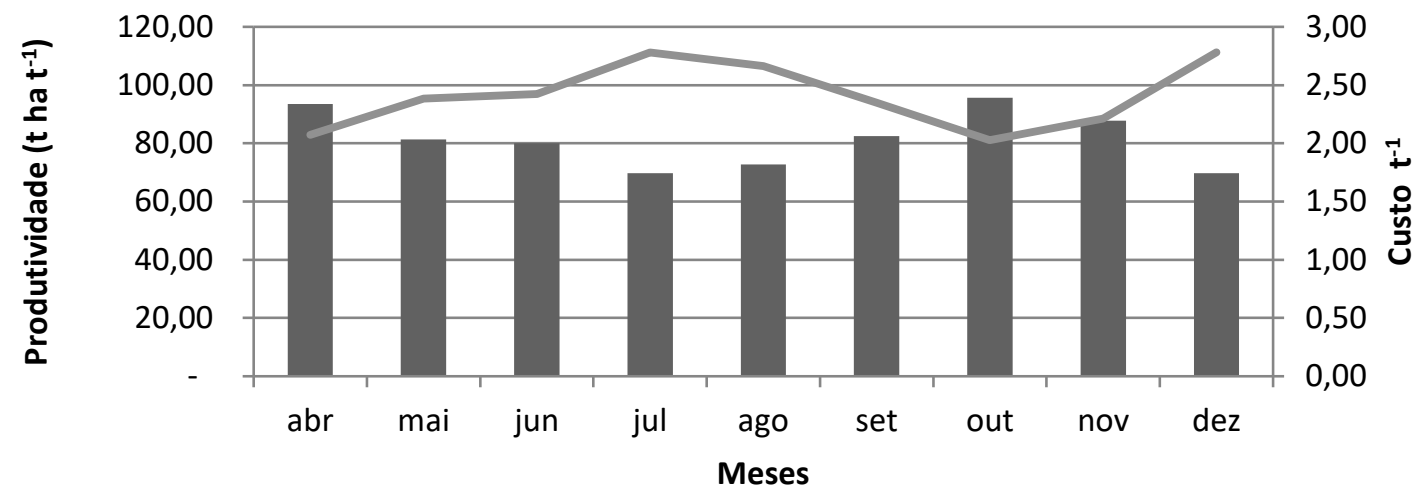

USD port-1 Produtividade

Figura 3. Relação entre o custo do corte mecanizado de uma tonelada e a produtividade da cana-de-açúcar durante os meses da safra 2013 Fonte: Dados obtidos da propriedade em estudo com base na safra 2013

Tabela 6. Modelagem para dimensionar o volume de horas necessárias para colheita de 1,5 milhões de toneladas na safra 2014 , em função das produtividades mensais da cana-de-açúcar

\begin{tabular}{|c|c|c|c|c|c|c|c|c|c|c|}
\hline \multicolumn{11}{|c|}{ Safra 2014} \\
\hline Indicadores & Unid. & Abr & Maio & Jun & Jul & Ago & Set & Out & Nov & Dez \\
\hline $\begin{array}{l}\text { Dias do Mês (dias } \\
\text { de safra) }\end{array}$ & Dias & 30 & 31 & 30 & 31 & 31 & 30 & 31 & 30 & 15 \\
\hline $\begin{array}{l}\text { Disponibilidade } \\
\text { Climática }\end{array}$ & $\%$ & 83 & 99 & 93 & 100 & 99 & 92 & 80 & 66 & 62 \\
\hline Dias Efetivos & Dias & 23 & 30 & 27 & 30 & 30 & 27 & 24 & 19 & 9 \\
\hline $\begin{array}{l}\text { Disponibilidade } \\
\text { Industrial }\end{array}$ & $\%$ & 94 & 97 & 97 & 97 & 97 & 97 & 96 & 95 & 94 \\
\hline $\begin{array}{l}\text { Moagem Mensal } \\
\text { Planejada }\end{array}$ & mil t h-1 & 161,8 & 204,1 & 186,1 & 207,9 & 204,1 & 183,5 & 163,5 & 130,2 & 58,8 \\
\hline $\begin{array}{l}\text { Produtividade } \\
\text { Média Mensal }\end{array}$ & $\mathrm{th}^{-1}$ & 99,63 & 108 & 117,3 & 110,9 & 99,60 & 92,73 & 83,55 & 78,08 & 86,97 \\
\hline $\begin{array}{l}\text { Características da } \\
\text { Colhedora }\end{array}$ & Unid. & Abr & Mai & Jun & Jul & Ago & Set & Out & Nov & Dez \\
\hline $\begin{array}{l}\text { Velocidade Média } \\
\text { de Colheita }\end{array}$ & $\mathrm{Km} \mathrm{h}^{-1}$ & 3,7 & 3,7 & 3,7 & 3,7 & 3,7 & 3,7 & 3,7 & 3,7 & 3,7 \\
\hline Utilização & $\%$ & 0,62 & 0,62 & 0,62 & 0,62 & 0,62 & 0,62 & 0,62 & 0,62 & 0,62 \\
\hline $\begin{array}{l}\text { Disponibilidade } \\
\text { Mecânica }\end{array}$ & $\%$ & 0,85 & 0,85 & 0,85 & 0,85 & 0,85 & 0,85 & 0,85 & 0,85 & 0,85 \\
\hline $\begin{array}{l}\text { Rendimento } \\
\text { Nominal }\end{array}$ & $\mathrm{th}^{-1}$ & 55 & 60 & 65 & 62 & 55 & 51 & 46 & 43 & 48 \\
\hline $\begin{array}{l}\text { Rendimento } \\
\text { Efetivo }\end{array}$ & $\mathrm{th}^{-1}$ & 29,1 & 31,6 & 34,3 & 32,4 & 29,1 & 27,1 & 24,4 & 22,8 & 25,4 \\
\hline $\begin{array}{l}\text { Rendimento Por } \\
\text { dia estimado }\end{array}$ & $\mathrm{th}^{-1}$ & 699 & 758 & 824 & 778 & 699 & 651 & 587 & 548 & 611 \\
\hline Colhedoras & № & 10 & 10 & 9 & 9 & 10 & 11 & 12 & 13 & 11 \\
\hline Horas Necessárias & Horas & 2.926 & 3.406 & 2.857 & 3.378 & 3.692 & 3.565 & 3.527 & 3.005 & 1.218 \\
\hline
\end{tabular}

Fonte: Dados obtidos da propriedade em estudo com base na safra 2014 


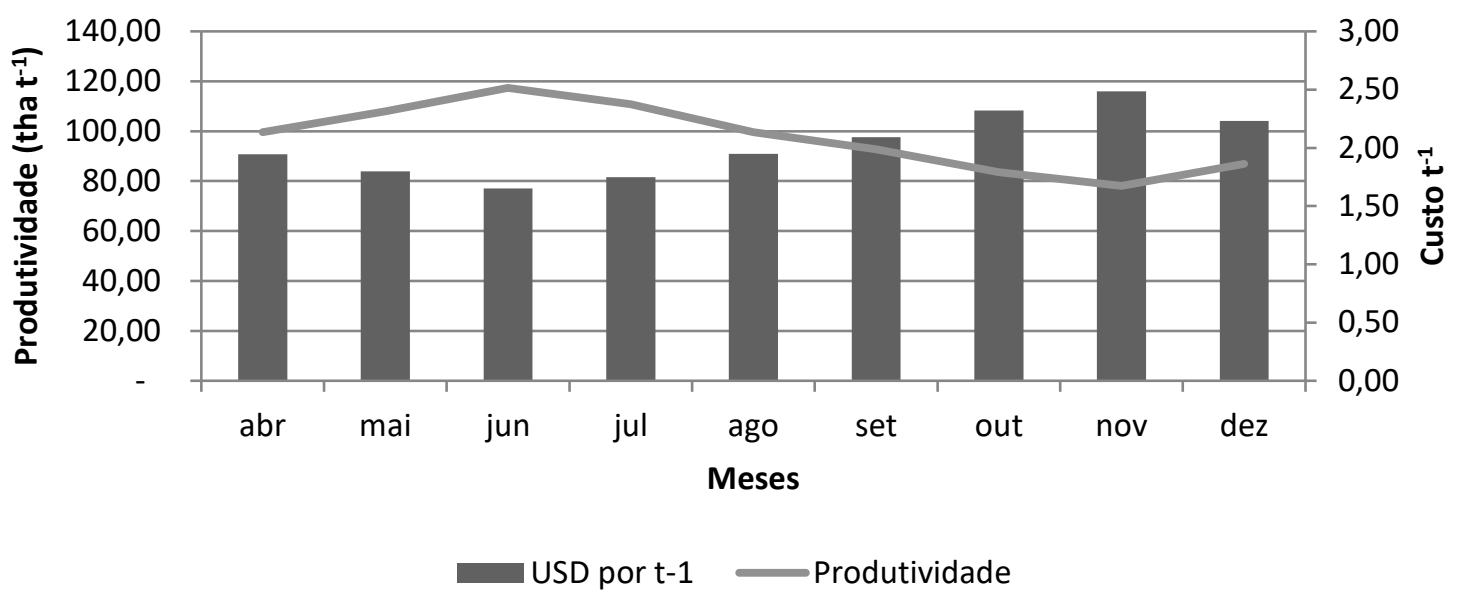

Figura 4. Relação entre o custo do corte mecanizado de uma tonelada e a produtividade da cana-de-açúcar durante os meses da safra 2014

Fonte: Dados obtidos da propriedade em estudo com base na safra 2014

A influência da produtividade no rendimento das colhedoras foi evidenciada pela redução de horas necessárias para a colheita do mesmo volume de cana nas diferentes no período analisado.

A Tabela 7 resume o volume de horas necessárias para colheita de 1,5 milhões de toneladas, considerando a colheita mês a mês das quatro safras.

Tabela 7. Quantidade de horas necessárias por mês para colheita de 1,5 milhões de toneladas por safra, considerando o período de 2011 a 2014

\begin{tabular}{ccccccccccc}
\hline Safra & Abr & Maio & Jun & Jul & Ago & Set & Out & Nov & Dez & Total \\
\hline 2011 & 4.006 & 5.036 & 4.096 & 4.660 & 4.442 & 4.564 & 4.158 & 3.423 & 1.671 & $\mathbf{3 6 . 0 5 7}$ \\
2012 & 3.658 & 4.001 & 3.746 & 3.904 & 4.079 & 4.466 & 4.565 & 3.681 & 1.728 & $\mathbf{3 3 . 8 2 7}$ \\
2013 & 3.513 & 3.854 & 3.459 & 3.368 & 3.450 & 3.518 & 3.634 & 2.653 & 952 & $\mathbf{2 8 . 4 0 2}$ \\
2014 & 2.926 & 3.406 & 2.857 & 3.378 & 3.692 & 3.565 & 3.527 & 3.005 & 1.218 & $\mathbf{2 7 . 5 7 4}$
\end{tabular}

Fonte: Dados obtidos da propriedade em estudo com base nas safras 2011 a 2014

A composição do custo da colhedora foi determinada por hora de utilização do equipamento. A Figura 5 revela a distribuição do custo por hora do equipamento, considerando o histórico das quarto safras e os custos a valores presentes. O custo realizado por hora no período foi de $U \$ 107,62$, divididos em custos fixos e variáveis. 


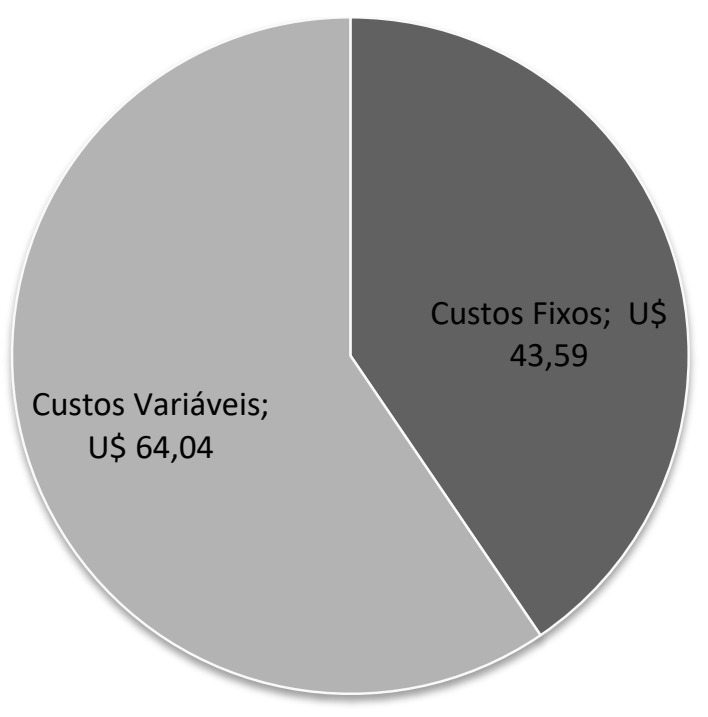

Figura 5. Distribuição do custo hora da colhedora de cana, agrupando-os em variáveis e fixos

Fonte: Dados obtidos da propriedade em estudo com base nas safras 2011 a 2014

Os custos fixos representam $40,5 \%$ do custo total da hora da colhedora, e os custos variáveis compreendem 59,5\%. Em relação à composição total do custo, podese dividir em seis categorias, sendo: a) Combustível; b) Lubrificante; c) Custo de reparo de manutenção [CRM]; d) Taxas; e) Depreciação; f) Salário operadores. A Figura 6 apresenta a representatividade de cada categoria em relação ao custo total.

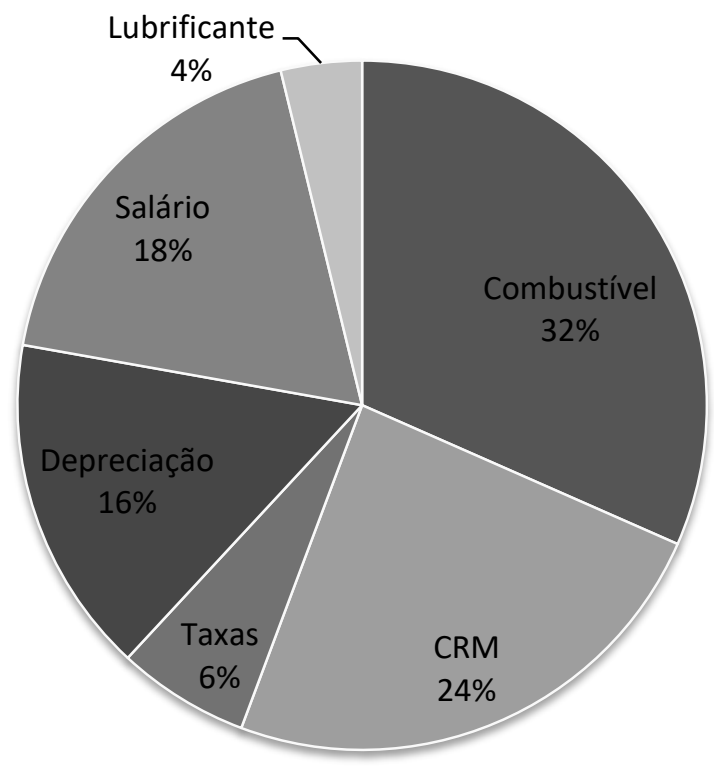

Figura 6. Distribuição do custo hora da colhedora de cana

Fonte: Dados obtidos da propriedade em estudo com base nas safras 2011 a 2014 
Dentre as seis categorias de custos, o combustível, lubrificante e reparo e manutenção [CRM]; são considerados variáveis, e estão diretamente relacionados a utilização dos equipamentos. Quanto maior a necessidade de horas para colheita das 1,5 milhões de toneladas, em função da produtividade agrícola, maior incidência destes custos variáveis, o que será determinante para o aumento do custo de corte mecanizado. Embora o custo fixo seja menor em função do maior uso de um ativo o qual o custo está vinculado, a menor produtividade do canavial demanda mais equipamentos e por consequência incremento dos custos fixos, como taxas, depreciações e salários.

A Figura 7 faz a relação do custo total do corte mecanizado de 1,5 milhões de toneladas em função da variação da produtividade agrícola ao longo das quatro safras. Observa-se relação direta entre o custo total do corte mecanizado e a produtividade agrícola, sendo o custo menor quando a produtividade agrícola é maior.

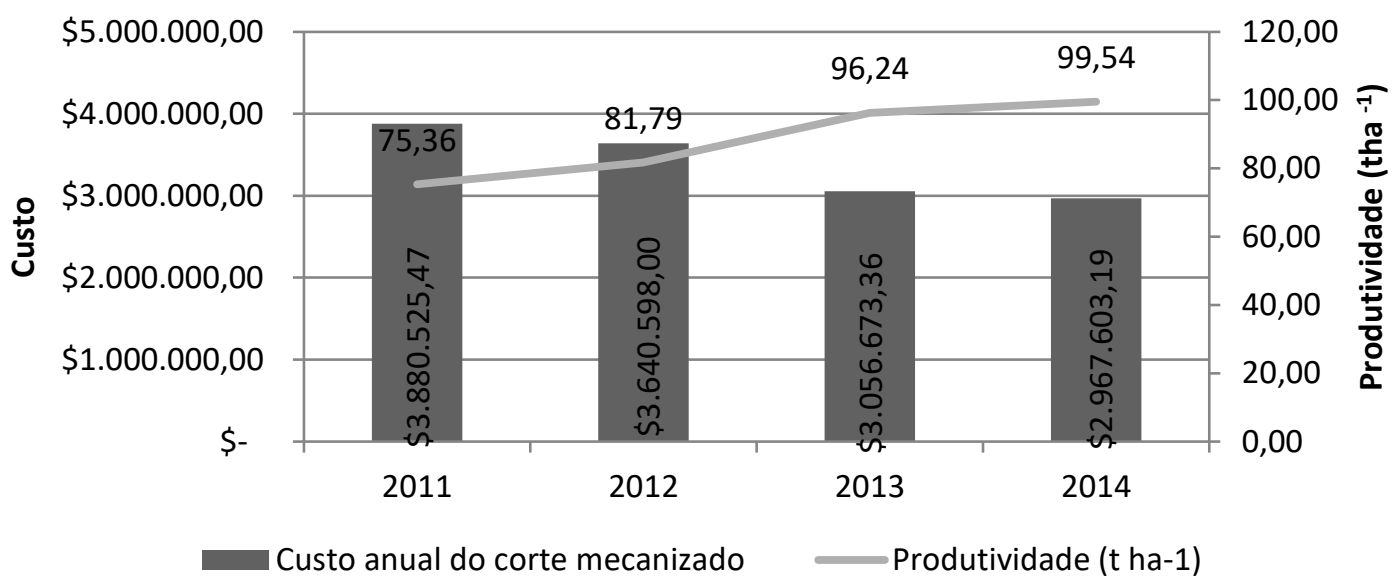

Figura 7. Custo total do corte mecanizado e produtividade agrícola da cana-de-açúcar durante as safras 2011; 2012; 2013 e 2014

Fonte: Dados obtidos da propriedade em estudo com base nas safras 2011 a 2014

A correlação da produtividade agrícola e o custo do corte mecanizado da empresa analisada está representada pela Figura 8. 


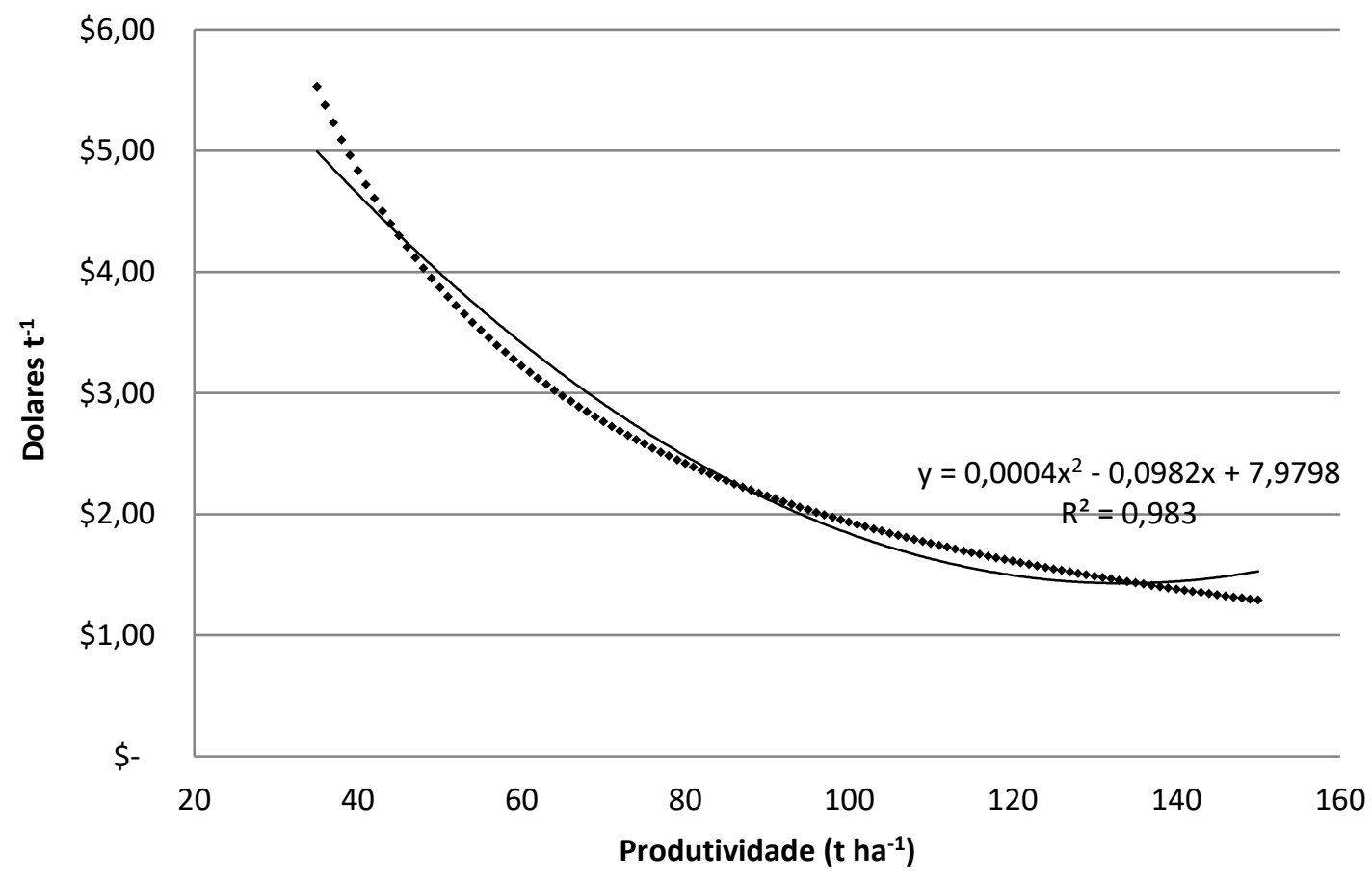

Figura 8. Custo do corte mecanizado de uma tonelada de cana-de-açúcar em função da produtividade do canavial

Fonte: Dados obtidos da propriedade em estudo com base nas safras 2011 a 2014

Conforme regressão acima, quanto maior a produtividade agrícola menor o custo do corte mecanizado.

Vale ressaltar que o trabalho não teve a intenção de explicar ou afirmar o aumento da produtividade, mas sim apenas utilizar como parâmetro para o rendimento das máquinas. Caso a produtividade se reduza, o rendimento também será afetado, conforme a curva de correlação apresentado na Figura 8.

Considerando a regressão quadrática (grau 2), temos a seguinte eq.(7):

$$
y=0,0012 x 2-0,3097 x+25,175
$$

Os valores resultantes estão apresentados na Tabela 8. 
Tabela 8. Custo do corte mecanizado em função da produtividade agrícola

\begin{tabular}{|c|c|c|}
\hline $\mathrm{TCH}$ & CUSTO & REDUÇÃO CUSTO \\
\hline & ------U\$ t $\mathbf{t}^{-1}$ & --------------\%------------- \\
\hline 10 & 7,036 & - \\
\hline 20 & 6,168 & 12,30 \\
\hline 30 & 5,377 & 12,80 \\
\hline 40 & 4,662 & 13,30 \\
\hline 50 & 4,022 & 13,70 \\
\hline 60 & 3,459 & 14,00 \\
\hline 70 & 2,972 & 14,10 \\
\hline 80 & 2,561 & 13,80 \\
\hline 90 & 2,226 & 13,10 \\
\hline 100 & 1,967 & 11,60 \\
\hline 110 & 1,784 & 9,30 \\
\hline 120 & 1,677 & 6,00 \\
\hline 130 & 1,646 & 1,80 \\
\hline 75,36 & 2,742 & \\
\hline 99,54 & 1,977 & 27,90 \\
\hline
\end{tabular}

Fonte: Dados obtidos da propriedade em estudo com base nas safras 2011 a 2014

A produtividade média na safra $2014 / 2015$ foi de $71,14 \mathrm{t} \mathrm{ha}^{-1}$ (UDOP, 2016). No caso de produtividades médias acima de 140 toneladas já começariam a influenciar o rendimento dos equipamentos. Caso isso seja realidade para os próximos anos, as empresas fornecedoras de equipamentos irão promover novas tecnologias para operação neste cenário.

\section{Conclusão}

Com base nas informações da empresa produtora de cana-de-açúcar analisada, foi possível concluir que quanto maior a produtividade agrícola, menor o custo do corte mecanizado, em função da necessidade de menor utilização da quantidade de horas de colhedoras para realizar o corte mecanizado na área estudada. Nas quatro safras analisadas, a empresa reduziu o custo do corte mecanizado em 27,9\% devido ao aumento da produtividade agrícola de 31,09\%. A redução do custo foi de 2,88 milhões de reais no período estudado. 


\section{Referências}

Companhia Nacional de Abastecimento (CONAB). 2014. Cana-de-Açúcar: Safra 2014/2015. Disponível em:

<http://www.conab.gov.br/conabweb/download/safra/1_levantamento1415_mai2008.pd f> Acesso em: 16 jun. 2015.

Instituto de Desenvolvimento Agroindustrial (IDEA). 2008.Transporte de cana de alto desempenho. Disponível em: <http://www.ideaonline.com.br/ideanews/> Acesso em: 05 jan. 2015.

Silva, J. G. 2002. Política para o setor sucroalcooleiro frente à crise: uma proposta alternativa para 0 Estado de São Paulo. Disponível em: <http://www.pt.org.br/site/assets/politica_setor_sucroalcooleiro.pdf.> Acesso em:12 ago. 2015.

Scopinho, R. A.; Eid, F. V.; Freitas, C. E.; Silva, P. R. C. 1999. Novas tecnologias e saúde do trabalhador: a mecanização do corte da cana-de-açúcar. Cadernos de Saúde Pública 15(1): 147-161.

União dos produtores de bioenergia [UDOP]. 2016. Como está a produtividade média de seus canaviais? Pesquisa quer apurar resultados. Disponível em: <http:// http://www.udop.com.br/index.php?item=noticias\&cod=1136808> Acesso em: 05 ago. 2016.

Veiga Filho, A. 1999. Estudo do processo de mecanização do corte na cana-deaçúcar: o caso do Estado de São Paulo, Brasil. Recitec 3(1): 74-99.

Vieira, G.; Simon, E. 2005. Possíveis impactos da mecanização no corte de cana-deaçúcar em conseqüência da eliminação gradativa da queima da palha. In: XLIII Congresso Brasileiro De Economia E Sociologia Rural, 2005, Ribeirão Preto. Anais do XLIII Congresso Brasileiro De Economia E Sociologia Rural. p. 1-9. 